\title{
Preparation of Single Substituted Phenyl Porphyrins Form Meso-Tetraphenyl Porphyrin-Synthetic Example from Symmetric Porphyrin into Asymmetric Porphyrins
}

\author{
Hui Lin, Xiaoting Chen, Yahong Wu, Shanling Tong, Sheng Hu, Jian Yu, Yan Yan* \\ College of Chemical Engineering \& Light Industry, Guangdong University of Technology, Guangzhou, China \\ Email: *yanyan600716@hotmail.com
}

How to cite this paper: Lin, H., Chen, X.T., Wu, Y.H., Tong, S.L., Hu, S., Yu, J. and Yan, Y. (2018) Preparation of Single Substituted Phenyl Porphyrins Form $\mathrm{Me}$ so-Tetraphenyl Porphyrin-Synthetic Example from Symmetric Porphyrin into Asymmetric Porphyrins. Open Journal of Inorganic Chemistry, 8, 21-27.

https://doi.org/10.4236/ojic.2018.81002

Received: October 26, 2017

Accepted: December 10, 2017

Published: December 13, 2017

Copyright $\odot 2018$ by authors and Scientific Research Publishing Inc. This work is licensed under the Creative Commons Attribution International License (CC BY 4.0).

http://creativecommons.org/licenses/by/4.0/

(c) $\underset{\mathrm{EY}}{\mathrm{EY}}$ Open Access

\begin{abstract}
Two asymmetric porphyrins, 5-(4-chloromethylphenyl)-10, 15, 20-triphenyl porphyrin and 5-(4-formylphenyl)-10, 15, 20-triphenyl porphyrin, were successfully prepared by the symmetric meso-tetraphenyl porphyrin and relative molecular configurations and properties were characterized by spectral determinations. This work presented an example for synthesis of asymmetric porphyrin derivatives from the symmetric porphyrin. Both asymmetric porphyrins are reactive in molecular assembly, the concerned reactions including alkylation with Grignard reagents, etherification with alcohols, aldol condensation and Mannich reaction for modification and enhancing their functionality. In this work, the reaction conditions were improved, synthetic strategy and route were confirmed.
\end{abstract}

\section{Keywords}

Asymmetric Porphyrin, Spectral Characterization, Redox, Chloromethylation, Formylation

\section{Introduction}

Matured technique for preparation of single substituted porphyrin was based on the Adler's method by using condensation of pyrrole with different ratio of substituted benzaldehydes. The resulted asymmetric porphyrins were excellent candidates in assembly of molecular devices, such as molecular wires [1] [2], sensitive reagent in photodynamic therapy (PDT) for tumors and cancers [3] [4], dyes in dye sensitized solar cells [5] [6]. In practice, the porphyrin reagents must 
be water-soluble and compatible with organisms, and therefore the asymmetric porphyrins must be modified to satisfy the condition in PDT. For overcoming the low yield limitation in synthesis of asymmetric porphyrins, a symmetric meso-tetraphenyl porphyrin (TPP) was selected as initiator, and an asymmetric porphyrin was successfully prepared by inducing a single substituent in para-position of one phenyl in the symmetric meso-tetraphenyl porphyrin. The resulted asymmetric product was 5-(4-chloromethylphenyl)-10, 15, 20-triphenyl porphyrin (CIMPTPP) with an active chlorine, and series of single substituted porphyrins can be derived from this asymmetric product, such as its derivative 5-(4-formylphenyl)-10, 15, 20-triphenyl porphyrin (FPTPP). According to reference method [7], the improved synthesis route was described in Scheme 1.

\section{Experimental}

Pyrrole was distilled and the clear single molecule distillation at $130^{\circ} \mathrm{C}-131^{\circ} \mathrm{C}$ was collected before using. Other reagents were purchased and used directly without further purification. IR spectra were recorded by Avatar 370 FT-IR spectrometer (Nicolet); A Bruker AVANCE III $400 \mathrm{MHz}$ magnetic resonance spectrometer was employed for ${ }^{1} \mathrm{H}$ NMR determinations; electronic spectra was performed by UV 2450 spectrophotometer (Shimadzu). Fluorescence spectra were recorded by a Fluoro Max-4 fluorescence spectrometer (HORIBA Jobin Yvon); a Bruker A200-9.5/12 Electron Paramagnetic Resonance spectrometer was selected to determine the paramagnetic properties. CV curves were recorded by A CHI660C electrochemical analyzer (Shanghai).
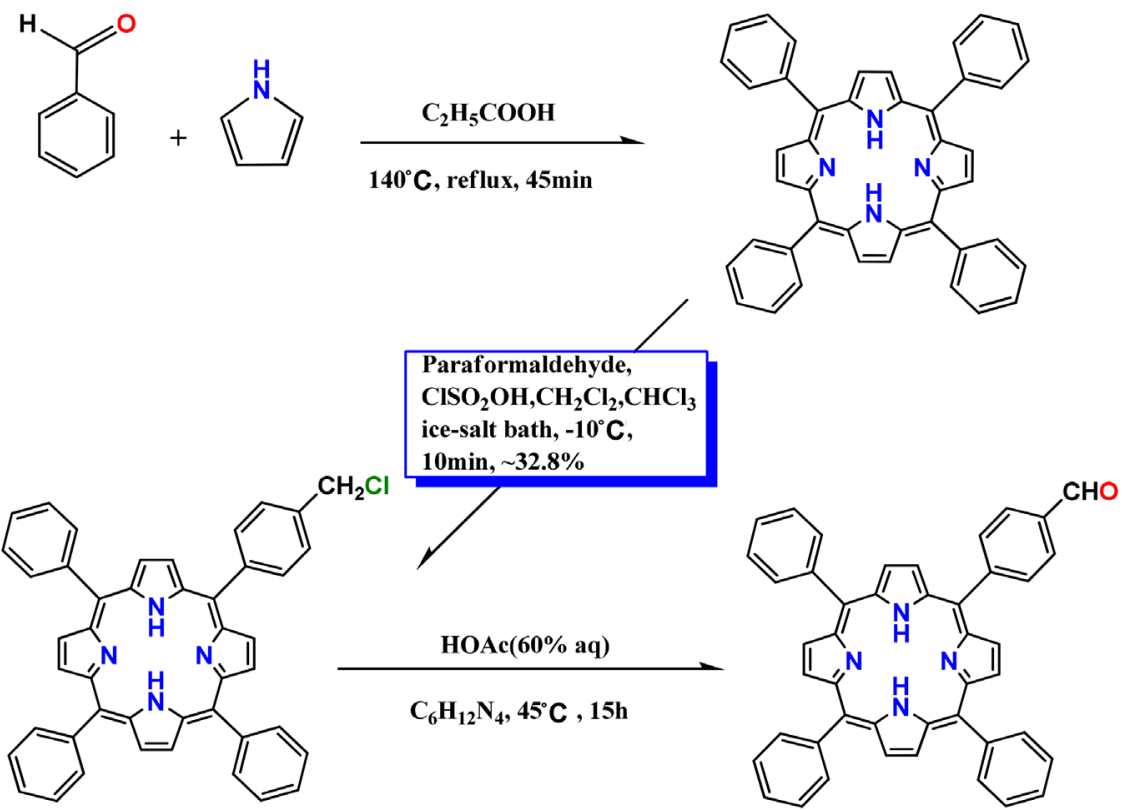

Scheme 1. The improved synthesis route of 5-(4-chloromethylphenyl)-10, 15, 20-triphenyl porphyrin (ClPTPP) and its derivative 5-(4-formylphenyl)-10, 15, 20-triphenyl porphyrin (FPTPP). 
Preparation of 5-(4-chloromethyl phenyl)-10, 15, 20-triphenyl porphyrin (ClMPTPP): $2.4 \mathrm{~g}$ paraformaldehyde ( $82.8 \mathrm{mmol}), \mathrm{NaCl}(0.3 \mathrm{~g}, 5.1 \mathrm{mmol}), 0.29 \mathrm{~g}$ $\mathrm{ZnCl}_{2}(2.1 \mathrm{mmol})$ and $10 \mathrm{~mL}$ dried $\mathrm{CH}_{2} \mathrm{Cl}_{2}$ were mixed well in a flask. The mixture was controlled at $-10^{\circ} \mathrm{C}$ by an ice-salt bath. Then $4.5 \mathrm{~mL} \mathrm{ClSO}{ }_{3} \mathrm{H}(68.19$ mmol) was added and the mixture was well dissolved by stirring. $5 \mathrm{~mL}$ dried $\mathrm{CHCl}_{3}$ with TPP [8] (0.3 g, $\left.0.489 \mathrm{mmol}\right)$ was slowly dripped into the reaction system under stirring within $5 \mathrm{~min}$. The reaction was kept for another $10 \mathrm{~min}$ and terminated by adding a large amount of ice-water. The resulted mixture was extracted by $\mathrm{CHCl}_{3}$ for 3 times, washed by water and then dried with $\mathrm{Na}_{2} \mathrm{SO}_{4}$ in turn to get the crude product. The product was furthermore purified by silica column chromatography with $\mathrm{MeOH}$ eluent. The second purple band was collected and the pure solid product in dark purple was obtained (100 mg, yield 32.8\%). ${ }^{1} \mathrm{H}-\mathrm{NMR}\left(400 \mathrm{MHz}, \mathrm{DMSO}-\mathrm{d}_{6}\right) \delta / \mathrm{ppm}$ : $8.858(8 \mathrm{H}, \beta-\mathrm{H}$ in pyrrole); $1.236\left(2 \mathrm{H}, \mathrm{N}-\mathrm{H}\right.$ in pyrrole), $3.589\left(2 \mathrm{H}\right.$ in $\left.-\mathrm{CH}_{2} \mathrm{Cl}\right), 6.959-7.209(8 \mathrm{H}$, ortho $\mathrm{H}$ in phenyl), $7.854-8.213(11 \mathrm{H}$, para and meta $\mathrm{H}$ in phenyl). The IR spectrum for ClMPTPP $/ \mathrm{cm}^{-1}: 3435.32\left(v_{\mathrm{N}-\mathrm{H}}\right.$ in pyrrole), $2948.31-2800\left(v_{\mathrm{C}-\mathrm{H}}\right.$ in $\left.-\mathrm{CH}_{2} \mathrm{Cl}\right)$, $1720.30,1605.80,1563.83,1434.11,1401.47,1274.91,1176.5,1110.63,1019.81$, $963.78,800.84,761.05,734.75$. The character vibration peaks of chloromythyl indicated the successfully synthesis of CIMPTPP.

Preparation of 5-(4-formylphenyl)-10, 15, 20-triphenyl porphyrin (FPTPP): $0.6 \mathrm{~g}$ (0.9 mmol) 5-(4-chloromethylphenyl)-10, 15, 20-triphenyl porphyrin (ClMPTPP), $1.26 \mathrm{~g}$ (9 mmol) hexamethylene-tetramine and $35 \mathrm{~mL}$ chloroform was mixed in a flask, after complete dissolution the solution was stirred continuously at $45^{\circ} \mathrm{C}$ for $15 \mathrm{~h}$. Then the solvent was removed by rotary vacuum evaporation, followed by adding $30 \mathrm{~mL} \mathrm{HOAc} \mathrm{(60 \% )} \mathrm{and} \mathrm{keeping} \mathrm{in} \mathrm{reflux} \mathrm{for} 10 \mathrm{~h}$. After cooling down and diluting with water until complete precipitation, the produced rough product in purple was separated by filtration and dried in a vacuum oven. Furthermore purification was carried out by chromatography as above description with a mix eluent of chloroform/mineral ether $(\mathrm{v} / \mathrm{v}=3 / 1)$, the second purple band was collected and after vacuum evaporation pure 5-(4-formylphenyl)-10, 15, 20-triphenyl porphyrin (FPTPP) in purple color was obtained in yield of $89 \%$ (0.5 g, $0.8 \mathrm{mmol}) .{ }^{1} \mathrm{H}-\mathrm{NMR}\left(400 \mathrm{MHz}, \mathrm{DMSO}-\mathrm{d}_{6}\right)$ $\delta /$ ppm: $-2.77(2 \mathrm{H} \mathrm{N}-\mathrm{H}$ in pyrrole); $6.82-7.77(11 \mathrm{H}$, para and meta $\mathrm{H}$ in phenyl); 8.02-8.63 (8H, ortho $\mathrm{H}$ in phenyl); $8.88(8 \mathrm{H}, \beta-\mathrm{H}$ in pyrrole); $10.34(1 \mathrm{H}$, single - PhCHO). The IR spectrum $/ \mathrm{cm}^{-1}: 3438.44\left(v_{\mathrm{N}-\mathrm{H}}\right.$ in pyrrole); $994.08\left(\delta_{\mathrm{N}-\mathrm{H}}\right.$ in pyrrole); 3053.09 ( $v_{\mathrm{C}-\mathrm{H}}$ in pyrrole); 3003.08 and 1440.38 ( $v_{\mathrm{C}-\mathrm{H}}$ in phenyl); $1597.34\left(v_{\mathrm{C}=\mathrm{C}}\right.$ in phenyl); and $1738.05\left(v_{\mathrm{C}=\mathrm{O}}\right.$ in $\left.\mathrm{PhCHO}\right)$.

\section{Results and Discussions}

Figure 1 was the compared UV-Vis spectra for FPTPP, CIMPTPP and TPP. All porphyrins presented one Soret band and four Q bands. Since only a hydrogen atom in para position of one peripheral phenyl of TPP was replaced by chloromethyl to form CIMPTPP, their UV-Vis spectra displayed high similarity in 


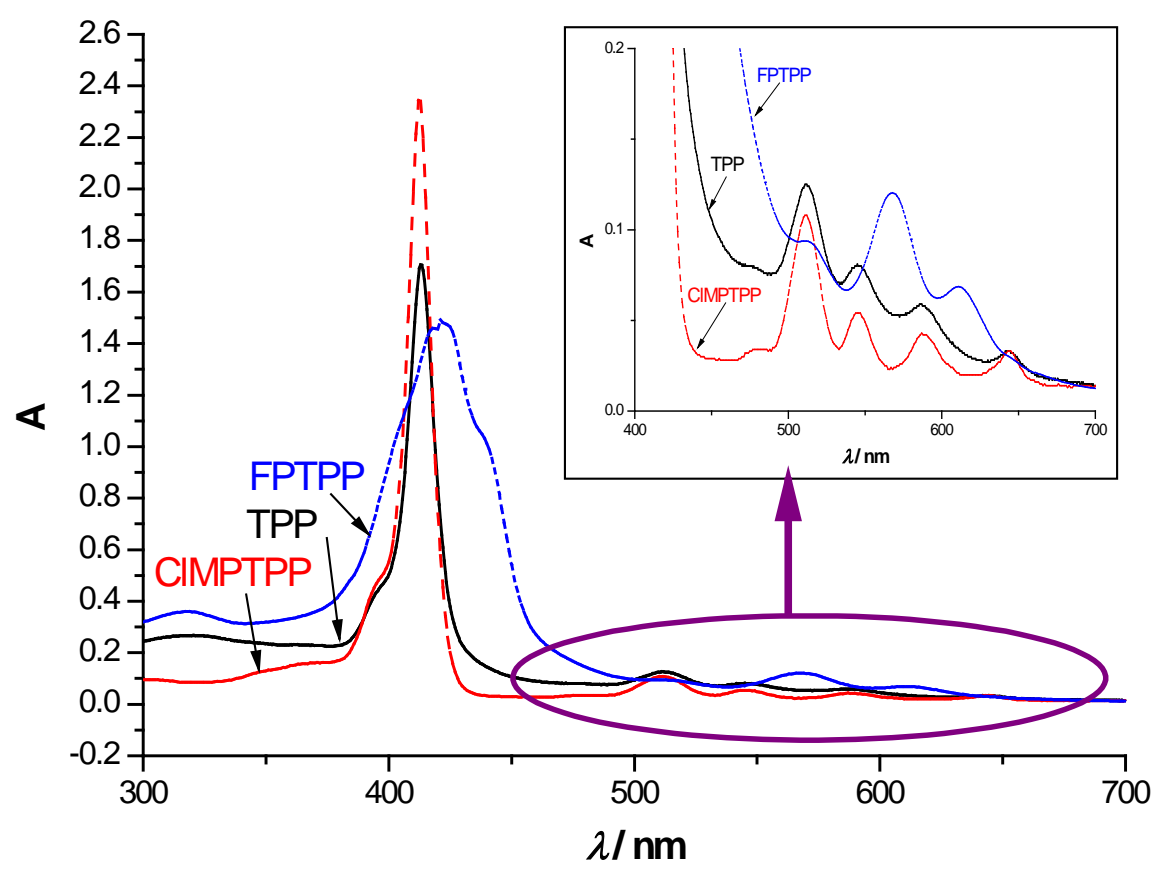

Figure 1. The UV-Vis spectra for 5-(4-formylphenyl)-10, 15, 20-triphenyl porphyrin (FPTPP, short dash), 5-(4-chloromethylphenyl)-10, 15, 20-triphenyl porphyrin (ClMPTPP, dash) and meso-tetraphenyl porphyrin (TPP, solid) in $\mathrm{CH}_{2} \mathrm{Cl}_{2}$ solution. For FPTPP: 421nm (Soret), 511, 568, 611 and 652nm (Q). For ClMPTPP: $412 \mathrm{~nm}$ (Soret), 512, 545, 587 and $644 \mathrm{~nm}$ (Q). For TPP: $413 \mathrm{~nm}$ (Soret), 511, 545, 587 and $644 \mathrm{~nm}(\mathrm{Q})$.

shapes and positions. But owing to formyl replacement, the spectrum for FPTPP displayed much differently both in shape and positions. The Soret band became more broadly, and all absorption peaks appeared with clear red-shift, excepting $\mathrm{Q}$ band at $511 \mathrm{~nm}$, the $\mathrm{Q}$ band at $652 \mathrm{~nm}$ nearly disappeared. This broadly spectral change can enhance light absorption of porphyrin derivatives, and in assembly of photosensitized molecular devices, the formyl substituted porphyrin should be considered preferentially. The influences of substituent replacement were more effectively reflected in photoluminescence. After replacement of one $\mathrm{H}$ atom in TPP by chloromethyl and formyl to form CIMPTPP and FPTPP, the emission spectra for the latter two were quenched in large scale (Figure 2), although this $\mathrm{H}$ atom was just at the para position of one peripheral phenyl! In the inner figure, both emission spectra for CIMPTPP and FPTPP were enlarged nearly 100 times. The reason for fluorescence quenching is arranged to be explored.

The compared EPR spectra for 5-(4-chloromethylphenyl)-10, 15, 20-triphenyl porphyrin (CIMPTPP, broad line) and meso-tetraphenyl porphyrin (TPP, thin line) in solid state were showed in Figure 3. Both TPP and ClMPTPP displayed a strong radical signal around $0.35 \mathrm{~T}$ orientated from the unpaired $\pi$ electron which was stabled by conjugated porphyrin ring; zero field splitting in porphyrin molecule resulted the asymmetric EPR signal. After substitution by chloromethyl, the EPR peak was furthermore split by $\mathrm{H}$ atoms in methylene $\left(-\mathrm{CH}_{2}-\mathrm{Cl}\right)$, the coupling result between single $\pi$ electron and protons. 


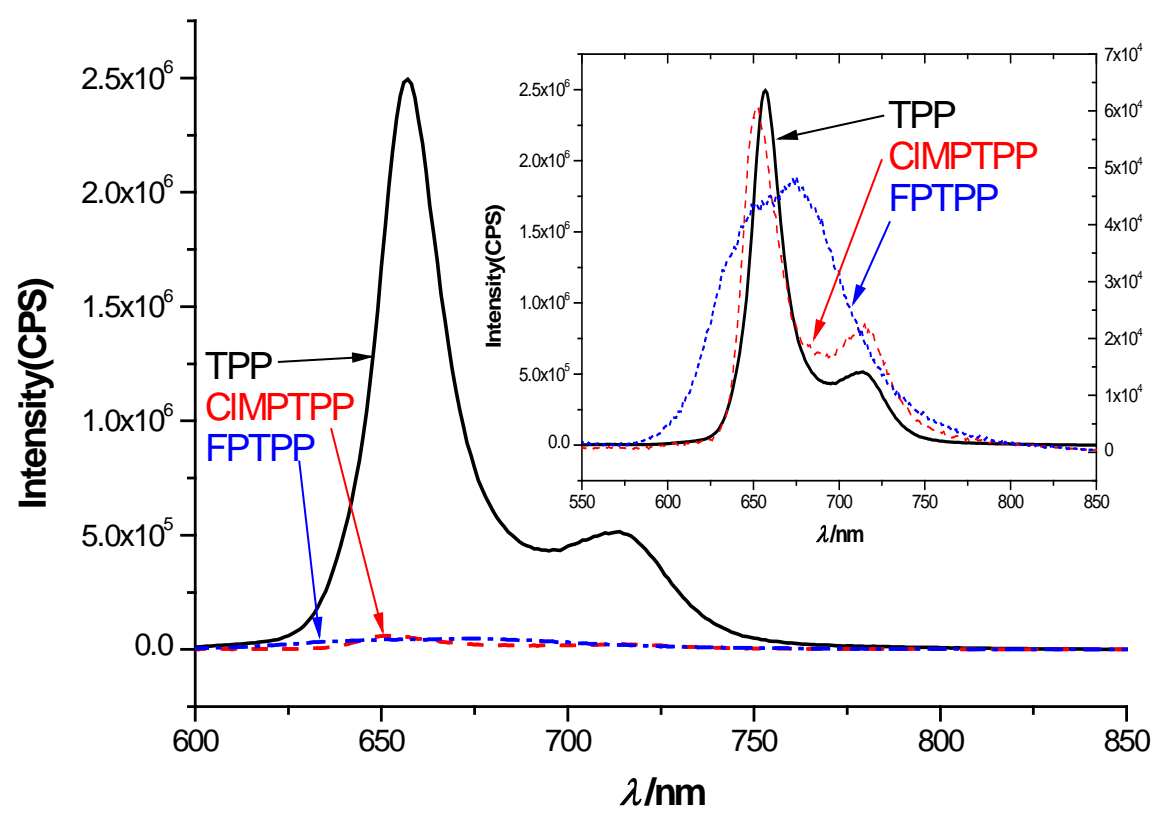

Figure 2. Emission spectra for for 5-(4-formylphenyl)-10, 15, 20-triphenyl porphyrin (FPTPP, $\lambda$ ex $=454 \mathrm{~nm}$, short dash), 5-(4-chloromethylphenyl)-10, 15, 20-triphenyl porphyrin (CIMPTPP, $\lambda$ ex $=431 \mathrm{~nm}$, dash) and meso-tetraphenyl porphyrin (TPP, $\lambda$ ex $=436$ $\mathrm{nm}$, solid) in $\mathrm{CH}_{2} \mathrm{Cl}_{2}$ solution. Emission peaks: For FPTPP: $685 \mathrm{~nm}$ (strong), without the weak peak. For ClMPTPP: 653 (strong) and 716 nm (weak). For TPP: 657 nm (strong) and $717 \mathrm{~nm}$ (weak).

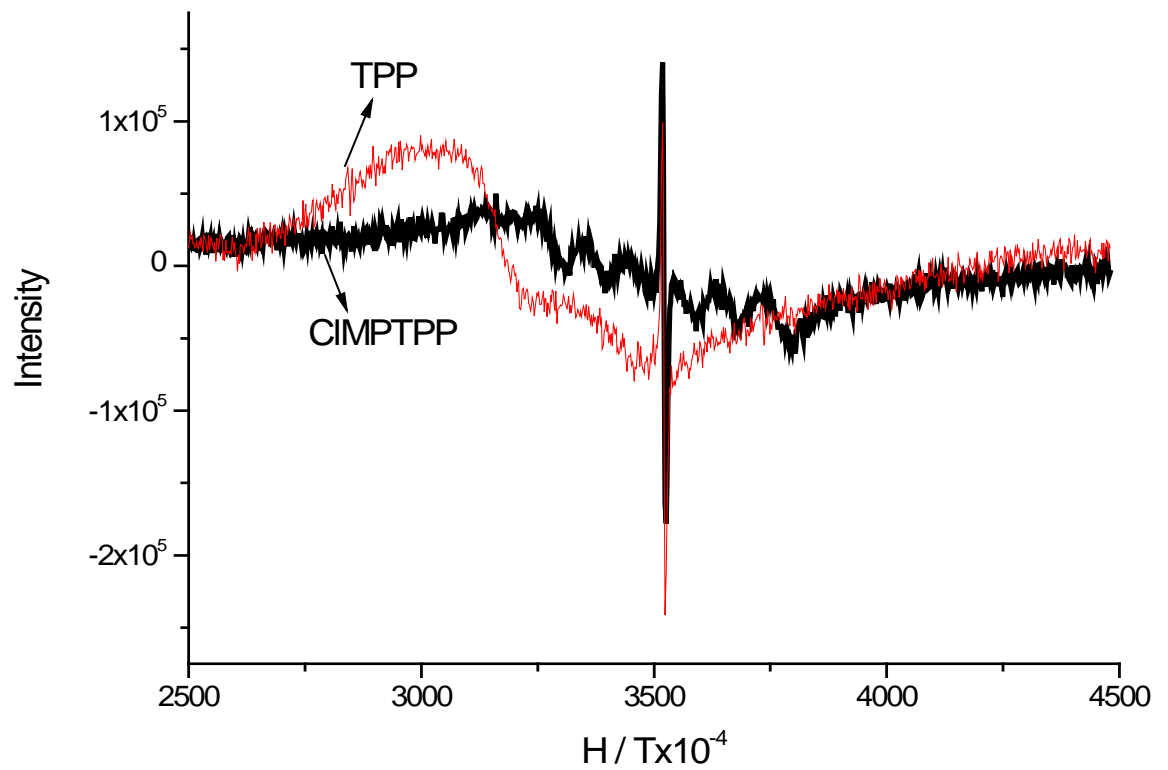

Figure 3. The compared EPR spectra in solid state for CIMPTPP (broad line) and TPP (thin line).

Figure 4 showed the cyclic voltammetric curves at $0.05-0.5 \mathrm{~V} / \mathrm{s}$. The curves clearly indicated that CIMPTPP gave three reductive peak around $-1.4 \mathrm{~V},-0.75$ $\mathrm{V}$ and $-0.25 \mathrm{~V}$. These redox potentials were associated with the following reactions: Por $^{+}+\mathrm{e}^{-}=$Por $^{0}+\mathrm{e}^{-}=$Por $^{-}+\mathrm{e}^{-}=$Por $^{2-}$ 


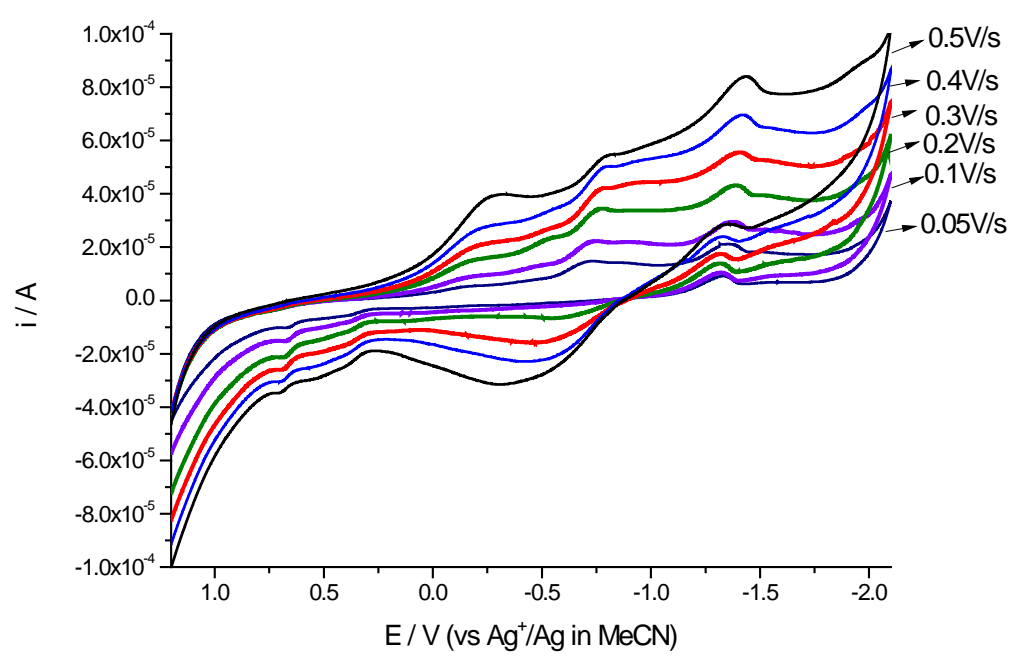

Figure 4. Cyclic voltammetric curves at different scan speeds for 5-(4-chloromethylphenyl)-10, 15, 20-triphenyl porphyrin in $\mathrm{CH}_{2} \mathrm{Cl}_{2}$ with TBAP (0.1 mol/L) vs. $\mathrm{Ag}^{+} / \mathrm{Ag}$ in $\mathrm{MeCN}$.

\section{Conclusion}

Two single substituted porphyrins, the asymmetric 5-(4-chloromethylphenyl)-10, 15, 20-triphenyl porphyrin (ClMPTPP) and 5-(4-formylphenyl)-10, 15, 20-triphenyl porphyrin (FPTPP) were successfully prepared from the symmetric meso-tetraphenyl porphyrin (TPP). The resulted asymmetric porphyrins were well characterized by spectral method. Photoluminescence experiment indicated that after chloromethyl and formyl replacement, the emission spectra were quenched in large scale for both asymmetric porphyrins. These asymmetric porphyrins can be selected as intermediates to assemble molecular blocks, such as porphyrin dimmers with bridge group of glycols, Grignard reagents, polyaldehydes, polyketones, and even polyamines. The porphyrin dendrimer can also be derived from these asymmetric porphyrins with bridging molecules possessing multiple side groups. These products would be potential molecule in photoelectric applications.

\section{Acknowledgements}

This work was supported by the Natural Science Fund in Guangdong Province (Grant No. 2017A030313071), the Excellent Young Teacher Development Project of Universities in Guangdong Province (Grant No. 261532106) and the Guangzhou Science and Technology Program (Grant No. 502150105).

\section{References}

[1] Maier, S., Fendt, L.-A., Zimmerli, L., Glatzel, T., Pfeiffer, O., Diederich, F. and Meyer, E. (2008) Nanoscale Engineering of Molecular Porphyrin Wires on Insulating Surfaces. Small, 4, 1115-1118. https://doi.org/10.1002/smll.200701259

[2] Vail, S.A., Krawczuk, P.J., Guldi, D.M., Palkar, A., Echegoyen, L., Tom, J.P.C., Fazio, M.A. and Schuster, D.I. (2005) Energy and Electron Transfer in Polyacety- 
lene-Linked Zinc-Porphyrin-Fullerene Molecular Wires. Chemistry-A European Journal, 11, 3375-3388. https://doi.org/10.1002/chem.200401348

[3] Bakar, M.B., Oelgemller, M. and Senge, M.O. (2009) Lead Structures for Applications in Photodynamic Therapy. Part 2: Synthetic Studies for Photo-Triggered Release Systems of Bioconjugate Porphyrin Photosensitizers. Tetrahedron, 65, 7064-7078. https://doi.org/10.1016/j.tet.2009.06.037

[4] Liang, X., Li, X., Yue, X. and Dai, Z. (2011) Conjugation of Porphyrin to Nanohybrid Cerasomes for Photodynamic Diagnosis and Therapy of Cancer. Angewandte Chemie International Edition, 50, 11622-11627.

https://doi.org/10.1002/anie.201103557

[5] Son, H.-J., Jin, S., Patwardhan, S., Wezenberg, S.J., Jeong, N.C., So, M., Wilmer C.E., Sarjeant, A.A., Schatz, G.C., Snurr, R.Q., Farha, O.K., Wiederrecht, G.P. and Hupp, J.T. (2013) Light-Harvesting and Ultrafast Energy Migration in Porphyrin-Based Metal-Organic Frameworks. Journal of the American Chemical Society, 135, 862-869. https://doi.org/10.1021/ja310596a

[6] Zervaki, G.E., Tsaka, V., Vatikioti, A., Georgakaki, I., Nikolaou, V., Sharma, G.D. and Coutsolelos, A.G. (2015) A Triazine Di(Carboxy)Porphyrin Dyad versus a Triazine Di(Carboxy)Porphyrin Triad for Sensitizers in DSSCs. Dalton Transactions, 44, 13550-13564. https://doi.org/10.1039/C5DT01141H

[7] Jia, X.L. (2006) Synthesis and Property Research of Novel Porphyrin. Master Thesis, Zhejiang University, Hangzhou, 43-47.

[8] Lindsey, J.S., Schreiman, I.C., Hsu, H.C., Kearney, P.C. and Marguerettaz, A.M. (1987) Rothemund and Adler-Longo Reactions Revisited: Synthesis of Tetraphenylporphyrins under Equilibrium Conditions. The Journal of Organic Chemistry, 52, 827-836. https://doi.org/10.1021/jo00381a022 